\title{
Perhitungan Unit Cost Pengembangan Sistem Informasi Pondok Pesantren Dengan Metode ABC (Activity Based Costing)
}

\author{
Muhammad Ainul Yaqin 1 , Muhammad Bagus Wicaksono ${ }^{2}$, Derida Elfraim Falahian ${ }^{3}$, Eryan \\ Rachman Hakim ${ }^{4}$ \\ Teknik Informatika, Universitas Islam Negeri (UIN) Maulana Malik Ibrahim Malang \\ Jl. Gajayana No. 50 Malang 65144 - Indonesia, Telp. +62 (341) 551-354 \\ 1yaqinov@ti.uin-malang.ac.id,216650124@student.uin-malang.ac.id,316650082@student.uin- \\ malang.ac.id, ${ }^{4} 16650044 @$ student.uin-malang.ac.id
}

\begin{abstract}
The purpose of this study is to describe and calculate the unit cost in developing the information system for Islamic boarding schools. This research uses a descriptive-quantitative approach. Data collection methods are observation and documentation. The descriptive approach in this study is used to analyze and interpret the data from observations and documentation that have been collected, while the quantitative approach in this study is used to explain the nominal unit cost calculation using the ABC (Activity Based Costing) method. In every development of an information system, the costs required are quite a lot and have several complex parameters, so that one of the management concepts is needed, namely cost accuracy. This becomes important for users of cost information to determine the cost effectiveness used by each unit as well as a reference price in further information system development, in this case the cost of developing an information system for Islamic boarding schools. The method we use in calculating unit costs is ABC (Activity Based Costing), where the calculation system charges costs for each activity involved before calculating product costs. The number of activities in developing a software or information system makes this method suitable to be applied in cost accuracy. The standard benchmark for the cost of procuring goods and services in this study is in accordance with government regulations and several observations, while the amount of salary costs follows the 2019 Minimum Standard Guidelines issued by INKINDO (National Association of Indonesian Consultants). The results of this study show that in developing the information system for Islamic boarding schools, the total cost required is Rp. 79,100,000.00 with a unit cost of Rp. 17,673,607.35.
\end{abstract}

Keywords: Information Systems, Unit Costs, Activity Based Costing

\begin{abstract}
Abstrak
Tujuan dari penelitian ini adalah untuk menguraikan serta menghitung biaya satuan (unit cost) dalam pengembangan sistem informasi pondok pesantren. Penelitian ini menggunakan pendekatan deskriptif-kuantitatif. Metode pengumpulan data berupa observasi dan dokumentasi. Pendekatan deskriptif pada penelitian ini digunakan untuk menganalisis dan menginterpretasi data hasil observasi dan dokumentasi yang telah dikumpulkan, sedangkan pendekatan kuantitatif pada penelitian ini digunakan untuk menjelaskan perhitungan nominal biaya satuan (unit cost) dengan menggunakan metode $A B C$ (Activity Based Costing). Dalam setiap pengembangan suatu sistem informasi, biaya yang dibutuhkan cukup banyak dan memiliki beberapa parameter yang kompleks, sehingga dibutuhkan salah satu konsep manajemen yakni pengakuratan biaya. Hal ini menjadi penting bagi pemakai informasi biaya untuk mengetahui efektifitas biaya yang digunakan tiap unit serta menjadi referensi harga dalam pengembangan sistem informasi selanjutnya, dalam kasus ini adalah biaya pengembangan sistem informasi pondok pesantren. Metode yang kami gunakan dalam menghitung unit cost adalah ABC (Activity Based Costing), dimana sistem perhitungannya dengan membebankan biaya pada setiap aktivitas yang terlibat terlebih dahulu sebelum menghitung biaya produk. Banyaknya aktivitas dalam mengembangkan suatu perangkat lunak atau sistem informasi membuat metode ini cocok untuk diterapkan dalam pengakuratan biaya. Patokan standard biaya pengadaan barang dan jasa pada penelitian ini sesuai dengan ketentuan pemerintah dan beberapa
\end{abstract}


observasi, sedangkan besaran biaya gaji mengikuti Pedoman Standard Minimal Tahun 2019 yang dikeluarkan oleh INKINDO (Ikatan Nasional Konsultan Indonesia). Hasil dari penelitian ini didapatkan bahwa dalam pengembangan sistem informasi pondok pesantren, biaya total yang dibutuhkan sebesar Rp. 79.100.000,00 dengan biaya per unit sebesar Rp. 17.673.607,35.

Kata kunci: Sistem Informasi, Biaya Satuan, Activity Based Costing

\section{PENDAHULUAN}

Perkembangan teknologi informasi tanpa disadari telah mengubah pola pikir dan pola hidup masyarakat. Kebutuhan untuk memperoleh informasi secara cepat dan akurat seakan telah menjadi bagian dari kebutuhan primer masyarakat di era modern seperti ini. Tentunya dengan bantuan teknologi informasi, penyajian informasi akan semakin mudah tersampaikan. Kemudahan memperoleh informasi ini sangat bermanfaat bagi manusia dalam meningkatkan produktivitas kerjanya, karena dengan adanya ketepatan informasi yang diperoleh tentu akan menambah akurasi pengambilan keputusan yang diambil, sehingga hal ini dapat mengurangi resiko yang mungkin terjadi pada kerja manusia [1]. Pentingnya informasi ini semakin jelas terlihat perannya ketika seseorang, kelompok, ataupun organisasi diharuskan untuk mengambil berbagai bentuk keputusan. Tentunya keputusan yang diambil akan semakin tepat dan efektif jika didukung oleh suplai informasi yang akurat dan representatif.

Pemanfaatan teknologi informasi inipun telah merambah ke semua bidang, salah satunya pada instansi pendidikan baik sekolah ataupun pondok pesantren. Setiap instansi pendidikan pasti membutuhkan suatu manajemen pengelolaan data-data yang dimiliki. Tentu data-data yang dimilikipun sangat kompleks sehingga dibutuhkan pengelolaan yang baik dan benar pula. Dan solusi dari kebutuhan tersebut adalah dengan menerapkan teknologi informasi dalam bentuk aplikasi sistem informasi [2]. Sistem informasi dapat diartikan sebagai sebuah sistem yang terintegrasi secara optimal dan berbasis komputer yang dapat menghimpun dan menyajikan berbagai jenis data yang akurat untuk berbagai macam kebutuhan.

Sistem informasi saat ini telah menjadi salah satu indikator keberhasilan kinerja suatu organisasi, bukan saja dari aspek operasional, melainkan juga hubungannya dengan kepercayaan pelanggan. Dalam kasus instansi pendidikan, pelanggan dapat diartikan sebagai siswa atau stakeholder yang terkait dengan instansi tersebut [3]. Organisasi yang didukung dengan teknologi informasi yang baik dan profesional akan memiliki nlai tambah berupa meningkatnya efisiensi dan efektifitas kerja, respon yang lebih cepat, dan penanganan masalah atau pengambilan keputusan yang lebih akurat.

Dalam pengembangan sistem informasi, suatu perusahaan atau organisasi dalam penelitian ini adalah pondok pesantren perlu menentukan strategi baik dalam pengerjaan maupun pembiayaan. Salah satu fokus pada penelitian ini adalah pengakuratan alokasi biaya pengembangan sistem informasi, dimana hal ini juga menjadi satu hal yang sangat penting sehingga pondok pesantren perlu menghitung secara rinci biaya setiap layanan sistem informasi yang diberikan untuk memudahkan dalam penyusunan anggaran dan mendapatkan alokasi biaya 
yang dikeluarkan terkelola dengan baik [4]. Hal tersebut dimaksudkan agar estimasi biaya tidak hanya sekedar perkiraan yang dapat mengakibatkan overhead karena perencanaan atau perhitungan yang tidak matang. Berdasarkan pada banyaknya aktivitas yang terjadi dalam mengembangkan suatu sistem informasi, maka untuk menghitung atau menentukan standard biaya satuan yang dikeluarkan, kami menggunakan metode ABC (Activity Based Costing) karena sistem perhitungannya dengan membebankan biaya pada setiap aktivitas yang terlibat terlebih dahulu sebelum menghitung biaya produk [5]. Selain itu biaya yang dibutuhkan juga dapat dihitung untuk setiap kompleksitasnya, sebagaimana kompleksitas sistem informasi merupakan satuan yang baku dalam dunia software. Sehingga selain mendapatkan harga dan biaya untuk pengembangan sistem informasi juga bisa menjadi acuan untuk pengembangan sistem informasi yang lain hanya dengan menggunakan nilai kompleksitas yang telah dihasilkan sebelumnya.

Secara garis besar perhitungan biaya dengan metode ABC yaitu: menentukan biaya awal untuk pengembangan produk. Setelah itu biaya dialokasikan ke seluruh aktivitas yang ada. Setelah didapatkan maka biaya aktivitas dihitung tiap unitnya. Biaya juga dihitung berdasar skala kompleksitasnya. Selain itu, kami penulis juga belum menemukan penelitian mengenai perhitungan biaya pengembangan sistem informasi di sektor pendidikan pondok pesantren. Untuk itu, diperlukan suatu penelitian yang membahas pengembangan sistem informasi di sektor tersebut. Implikasi penelitian ini adalah berupa pembuatan usulan membuat desain sistem perhitungan biaya aset tidak berwujud berupa sistem informasi milik organisasi pondok pesantren yang berasal dari pengembangan internal. Dengan demikian aset tidak berwujud yang berasal dari pengembangan internal dapat disajikan dalam laporan keuangan yang jelas dan akurat.

\section{METODOLOGI PENELITIAN}

\subsection{Biaya Satuan (Unit Cost)}

Unit Cost adalah biaya yang dikeluarkan oleh perusahaan untuk memproduksi, menyimpan, dan menjual satu unit produk tertentu. Biaya unit mencakup semua biaya tetap dan semua biaya variabel yang terlibat dalam produksi. Secara sederhana unit cost dapat diartikan sebagi biaya per unit produk atau biaya per pelayanan. Sedangkan menurut [1], unit cost didefinisikan sebagai hasil pembagian antara total cost yang dibutuhkan dengan jumlah unit produk yang dihasilkan. Produk yang dimaksud dapat berupa barang ataupun jasa. Biaya satuan ( unit cost ) adalah biaya yang dihitung untuk satu satuan produk pelayanan yang dihitung dengan cara membagi total cost dengan jumlah/kualitas output ( UC ( unit cost ) = TC ( total cost ) T/O ( total output ) ). Secara sederhana, biaya satuan sering kali disebut dengan " rata-rata". Yang merupakan hasil perhitungan dengan membagi biaya total dengan jumlah produksi. Hasil perhitungan biaya satuan terdapat dua macam biaya satuan yaitu biaya satuan normative dan biaya satuan aktual. 


\subsection{Sistem Informasi}

Sistem informasi adalah komponen-komponen yang saling berkaitan yang bekerja bersama-sama untuk mengumpulkan, mengolah, menyimpan, dan menampilkan informasi untuk mendukung pengambilan keputusan, koordinasi, pengaturan, analisa, dan visualisasi pada sebuah organisasi [3]. Sistem informasi adalah suatu sistem didalam suatu organisasi yang mempertemukan kebutuhan pengolahan transaksi harian yang mendukung fungsi operasi organisasi yang bersifat manajerial dengan kegiatan strategi dari suatu organisasi untuk dapat menyediakan kepada pihak luar tertentu dengan laporan-laporan yang diperlukan [4] Menurut [5] sistem informasi adalah pengaturan orang, data, proses, dan informasi (TI) atau teknologi informasi yang berinteraksi untuk mengumpulkan, memproses, menyimpan, dan menyediakan sebagai output informasi yang diperlukan untuk mendukung sebuah intansi atau organisasi.

\subsection{Pondok Pesantren}

Pondok Pesantren merupakan rangkaian kata yang terdiri dari pondok dan pesantren. Kata pondok (kamar, gubuk, rumah kecil) yang dipakai dalam Bahasa Indonesia dengan menekankan kesederhanaan bangunannya. Ada pula kemungkinan bahwa kata pondok berasal dari bahasa arab "fundūk" yang berarti ruang tempat tidur, wisma, atau hotel sederhana [6]. Pesantren mulanya tersebar hanya di beberapa pedesaan. Namun, seiring berkembangnya zaman, pesantren mengalami modernisasi. Pesantren dulunya hanya sebagai tempat tinggal yang digunakan untuk menimba ilmu dengan cara berdekatan dengan sang pengajar atau kyai, sekarang pesantren dianggap sebagai lembaga pendidikan yang mencakup ruang lingkup yang kompleks, untuk memenuhi standart nasional pondok pesantren, butuh beberapa proses pengembangan arsitektur data sistem informasi pondok pesantren agar menjadi lembaga pendidikan islam yang memadai.

Alur metode yang kami gunakan dalam penelitian ini adalah sebagaimana diagram dibawah ini.

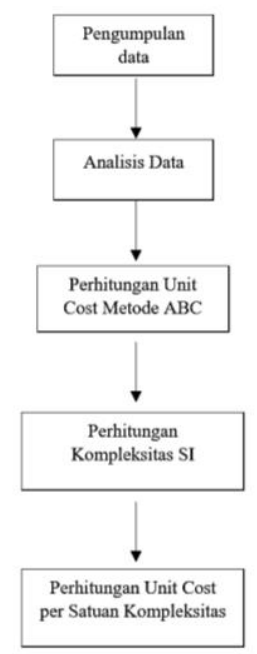

Gambar 1. Alur Metode Penelitian 


\subsection{Pengumpulan Data}

Pengumpulan data adalah cara untuk mengupulkan informasi, data, dan fakta-fakta yang berhubungan dengan penelitian. Pengumpulan data pada penelitian ini ada 2 macam, yakni data primer dan sekunder. Data primer yaitu pengumpulan data dari dokumentasi dan studi literatur, data sekunder yaitu sumber data yang didapat dari observasi. Adapun penjelasannya sebagai berikut:

a) Studi Literatur

Studi literatur yakni dengan membaca, memahami, menganalisis penelitian-penelitian yang telah dilakukan guna menemukan dasar teoritis yang akan dilakukan untuk menganalisis dalam penelitian ini.

b) Dokumentasi

Dokumentasi yakni barang-barang tertulis atau arsip-arsip yang berhubungan dengan penelitian ini, seperti data statistik, data gaji pegawai dll.

c) Observasi

Observasi yakni mencari sumber berupa sumber lisan yang didapat dari para ahli yang memahami tentang penelitian guna memperlancar proses penelitian. Observasi dapat dilakukan dengan wawancara atau melalui survei.

\subsection{Analisis Data}

Data yang telah didapatkan selanjutnya akan dianalisis, analisis data bisa dimulai dengan membuat Class Diagram sebagai sumber untuk menentukan unit sistem informasi. Selain itu class diagram juga diterapkan pada web service dan akan digunakan untuk menentukan skala kompleksitas. Adapun beberapa class diagramnya adalah sebagai berikut:

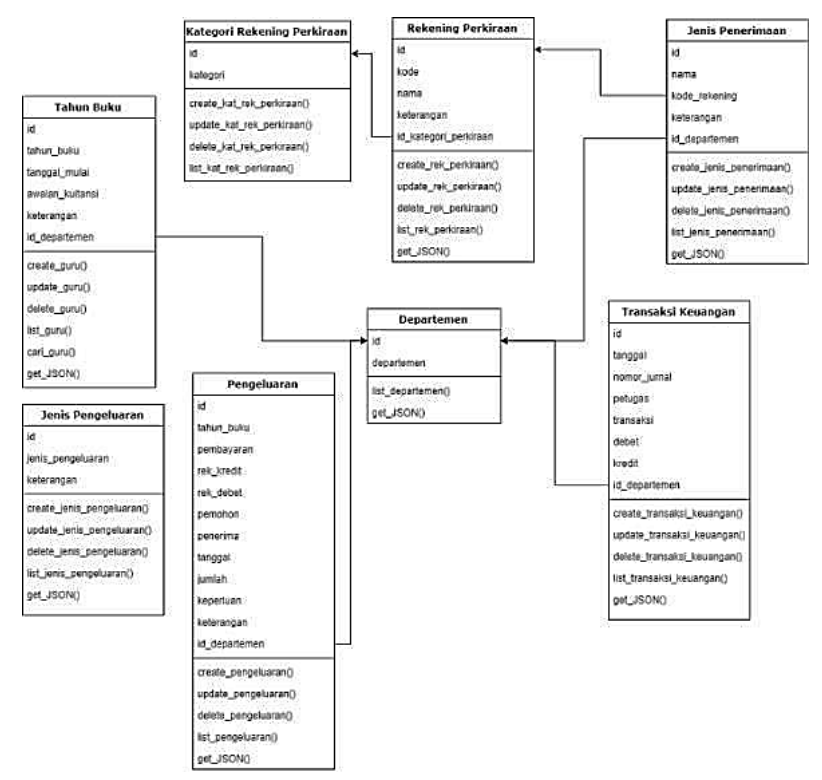

Gambar 2. Class Diagram Keuangan 
Jurnal Riset Sistem Informasi Dan Teknik Informatika (JURASIK)

Volume 5 Nomor 2 Agustus, pp 205-216

ISSN: 2527-5771/EISSN: 2549-7839

https://tunasbangsa.ac.id/ejurnal/index.php/jurasik

\begin{tabular}{|c|}
\hline Gurs \\
\hline ie \\
\hline no \\
\hline gurde \\
\hline 10_pelajaran \\
\hline id_stetiv__ouri \\
\hline Ketterangan \\
\hline crate_gunte? \\
\hline upcalo_anvo? \\
\hline delete_suruo: \\
\hline list_gondul \\
\hline can_gurv0 \\
\hline get_ISONo: \\
\hline
\end{tabular}

\begin{tabular}{|c|}
\hline Delajaran \\
\hline id_peisjeran \\
\hline singketan \\
\hline nana \\
\hline sitat: \\
\hline ketorengàn \\
\hline atatus: \\
\hline crezte_ootajarano \\
\hline update Defferano \\
\hline delose_pelajaran!) \\
\hline Ist_petajarant0 \\
\hline get_json) \\
\hline
\end{tabular}

Jam

\begin{tabular}{|c|}
\hline $\begin{array}{l}\text { id } \\
\text { walsu }\end{array}$ \\
\hline create_jano \\
\hline update_jam0 \\
\hline delote jarn|) \\
\hline lat jam0 \\
\hline get_J9ON) \\
\hline
\end{tabular}
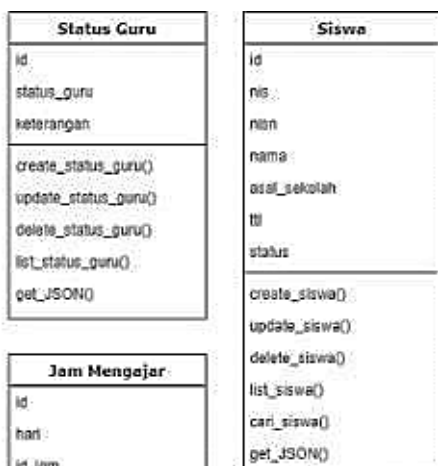

indam

14. ouru:

ic_eotiotian

thut alaran

temeste

deat:_jan_mitengalaro

udsalejam_mancalarto

Celate jam_mengyart?

Istjan_mangalaro

cart_an_mengajar

get_Json:

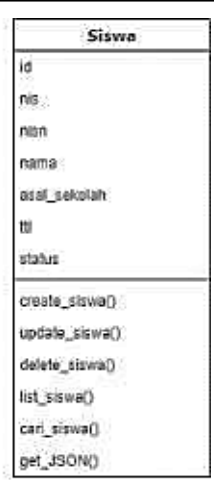

Gambar 3. Class Diagram Akademik
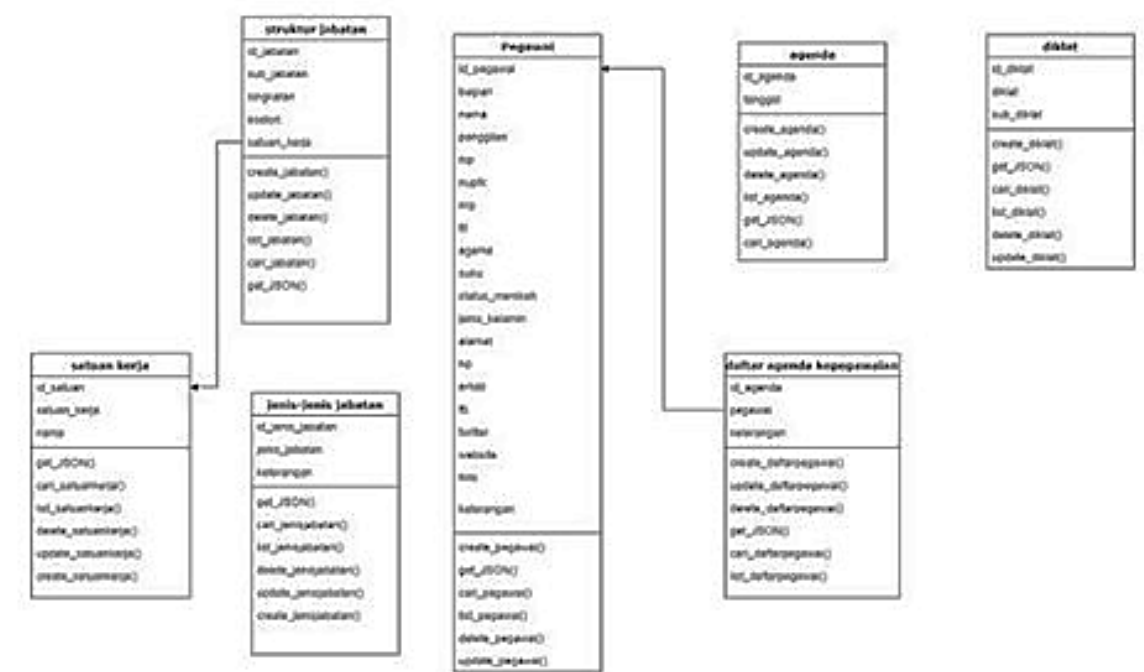

Gambar 4. Class Diagram Pegawai

\subsection{Perhitungan Unit Cost Metode ABC}

Adapun tahap perhitungan Unit Cost dengan metode ABC adalah sebagaimana diagram dibawah ini.

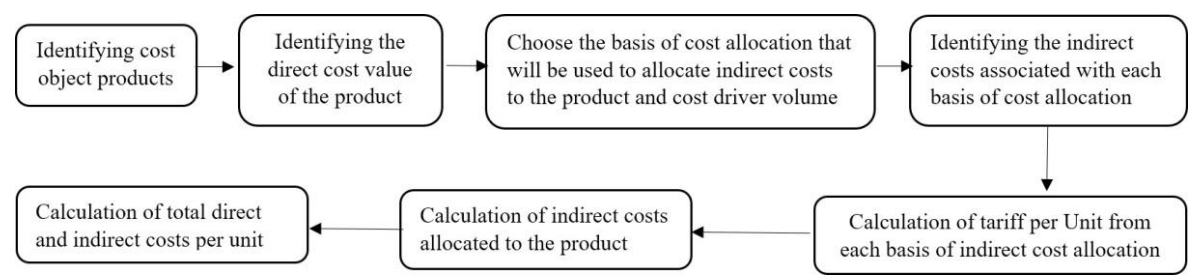

Gambar 5. Alur Metode ABC

Perhitungan Unit Cost Pengembangan SI Pondok Pesantren Metode ABC (Derida Elfraim Falahian) |210 
Keterangan :

a) Mengidentifikasi produk yang menjadi objek biaya.

b) Mengidentifikasi nilai biaya langsung produk. Dari biaya langsung yang sudah ditentukan, maka dilanjutkan menentukan nilai/ value biaya tersebut.

c) Memilih dasar alokasi biaya yang akan digunakan untuk mengalokasikan biaya tidak langsung ke produk dan volume cost driver. Setiap Cost driver dirinci untuk jumlah dan volume serta nilainya.

d) Mengidentifikasi biaya tidak langsung yang berkaitan dengan setiap dasar alokasi biaya.

e) Menghitung tarif per Unit dari setiap dasar alokasi biaya tidak langsung.

f) Menghitung biaya tidak langsung yang dialokasikan ke produk.

g) Menghitung total biaya tiap unit langsung dan tak langsung.

\subsection{Perhitungan Kompleksitas Sistem Informasi}

Skala kompleksitas banyak macamnya, salah satunya yakni kompleksias kode (Codescale) yang merepresentasikan tingkat kerumitan kode pada suatu program. Secara umum kode program direpresentasikan berdasarkan standar Object Oriented Programming (OOP). Berdasarkan 0OP, struktur kode program dapat digambarkan dalam bentuk class diagram. Class diagram terdiri dari method (Method), atribut (Attribute), dan relasi (Relation). Codescale dapat diformulasikan sebagai berikut:

$$
\text { Codescale }=\left(0.637 \cdot \sum \text { Method }\right)+\left(0.258 \cdot \sum \text { Attribute }\right)+\left(0.105 \cdot \sum \text { Relation }\right)
$$

\subsection{Perhitungan Unit Cost per Satuan Kompleksitas}

Tujuan utama dari penelitian ini yakni mengetahui Unit Cost / biaya satuan untuk sistem informasi sekolah berdasarkan kompleksitasnya. Adapun total biaya yang sudah didapatkan dari perhitungan ABC pada akhirnya dibagi dengan kompleksitas yang diukur, baik dari method, proses bisnis atau kodenya. Dan pada penelitian ini yang digunakan adalah kompleksitas kode.

\section{HASIL DAN PEMBAHASAN}

\subsection{Perhitungan Unit Cost dengan Metode $A B C$}

\subsubsection{Mengidentifikasi Produk yang Menjadi Objek Biaya}

Tabel 1. Produk (Sistem Informasi) yang menjadi objek biaya

\begin{tabular}{|c|l|c|}
\hline No & \multicolumn{1}{|c|}{ Jenis SI } & Jml Unit \\
\hline 1. & Admin Dashboard System (ADS) & 5 \\
\hline 2. & Santri Dashboard System (SDS) & 3 \\
\hline 3. & Asatidz Dashboard System (AZDS) & 1 \\
\hline
\end{tabular}


https://tunasbangsa.ac.id/ejurnal/index.php/jurasik

\begin{tabular}{|c|l|c|}
\hline No & \multicolumn{1}{|c|}{ Jenis SI } & Jml Unit \\
\hline 4. & Manajemen Sarana Prasarana (MSP) & 2 \\
\hline 5. & Manajemen Keuangan (MK) & 2 \\
\hline 6. & Jurnal Umum (JU) & 2 \\
\hline 7. & Manajemen Pondok Pesantren (MPP) & 6 \\
\hline 8. & Laporan Keungan (LK) & 3 \\
\hline 9. & Rekapitulasi (RK) & 10 \\
\hline 10. & Manajemen Santri Baru (MSB) & 2 \\
\hline 11. & Manajemen Aplikasi (MA) & 7 \\
\hline
\end{tabular}

\subsubsection{Mengidentifikasi Nilai Biaya Langsung Produk}

Tabel 2. Nilai Biaya Langsung Produk

\begin{tabular}{|c|l|c|c|c|c|c|}
\hline No & Jenis SI & Biaya Langsung & $\begin{array}{c}\text { Jam } \\
\text { Pengembangan }\end{array}$ & $\begin{array}{c}\text { Biaya } \\
\text { Konsumsi }\end{array}$ & Biaya Utama & \%waktu \\
\hline 1. & ADS & $2.637 .362,64$ & 600 & $250.000,00$ & $2.887 .362,64$ & $13 \%$ \\
\hline 2. & SDS & $527.472,53$ & 120 & $100.000,00$ & $627.472,53$ & $3 \%$ \\
\hline 3. & AZDS & $2.197 .802,20$ & 500 & $300.000,00$ & $2.497 .802,20$ & $11 \%$ \\
\hline 4. & MSP & $1.318 .681,32$ & 300 & $400.000,00$ & $1.718 .681,32$ & $7 \%$ \\
\hline 5. & MK & $1.978 .021,98$ & 450 & $350.000,00$ & $2.328 .021,98$ & $10 \%$ \\
\hline 6. & JU & $1.142 .857,14$ & 260 & $250.000,00$ & $1.392 .857,14$ & $6 \%$ \\
\hline 7. & MPP & $1.758 .241,76$ & 400 & $100.000,00$ & $1.858 .241,76$ & $9 \%$ \\
\hline 8. & LK & $1.318 .681,32$ & 300 & $250.000,00$ & $1.568 .681,32$ & $7 \%$ \\
\hline 9. & RK & $527.472,53$ & 120 & $400.000,00$ & $927.472,53$ & $3 \%$ \\
\hline 10 & MSB & $3.164 .835,16$ & 720 & $300.000,00$ & $3.464 .835,16$ & $16 \%$ \\
\hline 11. & MA & $3.164 .835,16$ & 780 & $350.000,00$ & $3.778 .571,43$ & $17 \%$ \\
\hline & TOTAL & $20.000 .000,00$ & 4550 & $3.050 .000,00$ & $23.050 .000,00$ & $100 \%$ \\
\hline
\end{tabular}

Mengelompokkan biaya objek yang menjadi objek biaya lalu dari biaya langsung yang sudah ditentukan, maka dilanjutkan menentukan nilai/ value biaya tersebut.

\subsubsection{Memilih Dasar Alokasi Biaya yang Akan Digunakan Untuk Mengalokasikan Biaya Tidak Langsung ke Produk dan Volume Cost Driver}

Tabel 3. Identifikasi Aktivitas dan Satuannya

\begin{tabular}{|l|l|l|}
\hline No. & \multicolumn{1}{|c|}{ Jenis Aktivitas } & \multicolumn{1}{c|}{ Satuan } \\
\hline 1. & Komunikasi (K) & Jam Komunikasi (JK) \\
\hline 2. & Pengarahan/Pengawasan (P) & Jam Pengawasan (JP) \\
\hline 3. & Analisis System (AS) & Jumlah Proses (JPr) \\
\hline 4. & Design Frontend (DF) & Sketch Design (SD) \\
\hline 5. & Dokumentasi Program (DP) & Sketch Dokumen (SDoc) \\
\hline 6. & Write Help Guide (WH) & Jumlah Lembar (JL) \\
\hline 7. & Pengaturan Jaringan (PJ) & Jam Pengaturan (JP) \\
\hline 8. & Coding System (CS) & Jumlah Method (JM) \\
\hline 9. & Implementasi (I) & Jumlah Fitur (JF) \\
\hline 10. & Testing (T) & Jumlah Uji (JU) \\
\hline
\end{tabular}


Tabel 4. Dasar Alokasi Biaya yang Akan Digunakan Untuk Mengalokasikan Biaya Tidak Langsung

\begin{tabular}{|c|c|c|c|c|c|c|c|c|c|c|c|}
\hline No & Jenis SI & JK & JP & JPr & SD & SDoc & JL & JP & JM & JF & JU \\
\hline 1. & ADS & 23 & 5 & 10 & 12 & 20 & 23 & 3 & 50 & 10 & 9 \\
\hline 2. & SDS & 43 & 2 & 12 & 2 & 2 & 12 & 2 & 40 & 20 & 3 \\
\hline 3. & AZDS & 21 & 3 & 2 & 3 & 12 & 1 & 4 & 30 & 32 & 5 \\
\hline 4. & MSP & 34 & 1 & 2 & 5 & 14 & 2 & 5 & 40 & 11 & 7 \\
\hline 5. & MK & 5 & 4 & 10 & 7 & 5 & 6 & 7 & 20 & 16 & 2 \\
\hline 6. & JU & 9 & 1 & 4 & 8 & 7 & 9 & 2 & 35 & 11 & 5 \\
\hline 7. & MPP & 10 & 3 & 10 & 9 & 3 & 3 & 9 & 30 & 9 & 1 \\
\hline 8. & LK & 20 & 2 & 30 & 4 & 9 & 7 & 5 & 20 & 8 & 6 \\
\hline 9. & RK & 5 & 5 & 9 & 2 & 5 & 1 & 3 & 10 & 4 & 7 \\
\hline 10. & MSB & 20 & 4 & 9 & 4 & 3 & 3 & 2 & 50 & 9 & 4 \\
\hline 11. & MA & 25 & 9 & 20 & 5 & 3 & 3 & 4 & 90 & 19 & 3 \\
\hline & TOTAL & 215 & 39 & 118 & 61 & 83 & 70 & 46 & 415 & 149 & 52 \\
\hline
\end{tabular}

Setiap Cost driver dirinci untuk jumlah dan volume serta nilainya. Perinciannya berdasarkan satuan yang digunakan oleh tiap bagian system informasi.

\subsubsection{Mengidentifikasi Biaya Tidak Langsung yang Berkaitan dengan Setiap Dasar Alokasi Biaya}

Tabel 5. Biaya tidak langsung yang berkaitan dengan setiap dasar alokasi biaya

\begin{tabular}{|c|l|l|}
\hline No. & Aktivitas & \multicolumn{1}{c|}{ Biaya } \\
\hline 1. & K & $5.000 .000,00$ \\
\hline 2. & P & $6.250 .000,00$ \\
\hline 3. & AS & $4.900 .000,00$ \\
\hline 4. & DF & $6.500 .000,00$ \\
\hline 5. & DP & $3.100 .000,00$ \\
\hline 6. & WH & $3.000 .000,00$ \\
\hline 7. & PJ & $10.700 .000,00$ \\
\hline 8. & CS & $7.550 .000,00$ \\
\hline 9. & I & $4.000 .000,00$ \\
\hline 10. & T & $5.050 .000,00$ \\
\hline & Total & $56.050 .000,00$ \\
\hline
\end{tabular}

Biaya tidak langsung berasal dari gaji pekerja yang didapat dari sumbersumber terpercaya salah satunya Pedoman Standard Minimal Tahun 2019 oleh INKINDO.

\subsubsection{Menghitung Tarif per Unit dari Alokasi Biaya Tidak Langsung}

Tabel 6. Tarif per Unit dari Setiap Dasar Alokasi Biaya Tidak Langsung

\begin{tabular}{|c|l|l|r|r|r|c|}
\hline No & Aktivitas & \multicolumn{1}{|c|}{ Biaya } & \multicolumn{1}{|c|}{ Volume } & Satuan & Pool Rate & Satuan \\
\hline 1. & K & $5.000 .000,00$ & 215 & Jam & $23.255,81$ & Per jam \\
\hline
\end{tabular}


Jurnal Riset Sistem Informasi Dan Teknik Informatika (JURASIK)

Volume 5 Nomor 2 Agustus, pp 205-216

ISSN: 2527-5771/EISSN: 2549-7839

https://tunasbangsa.ac.id/ejurnal/index.php/jurasik

\begin{tabular}{|c|c|c|c|c|c|c|}
\hline No & Aktivitas & Biaya & Volume & Satuan & Pool Rate & Satuan \\
\hline 2. & $\mathrm{P}$ & $6.250 .000,00$ & 39 & Hari & $160.256,41$ & Per hari \\
\hline 3. & AS & $4.900 .000,00$ & 118 & Proses & $41.525,42$ & Per proses \\
\hline 4. & DF & $6.500 .000,00$ & 61 & Sketch & $106.557,38$ & Per sketch \\
\hline 5. & $\mathrm{DP}$ & $3.100 .000,00$ & 83 & Sketch & $37.349,40$ & Per sketch \\
\hline 6. & WH & $3.000 .000,00$ & 70 & Lembar & $42.857,14$ & Per lembar \\
\hline 7. & $\mathrm{PJ}$ & $10.700 .000,00$ & 46 & Jam & $232.608,70$ & Per jam \\
\hline 8. & CS & $7.550 .000,00$ & 415 & Method & $18.192,77$ & Per method \\
\hline 9. & I & $4.000 .000,00$ & 149 & Fitur & $26.845,64$ & Per fitur \\
\hline 10. & $\mathrm{~T}$ & $5.050 .000,00$ & 52 & $\mathrm{Uji}$ & $97.115,38$ & Per uji \\
\hline & TOTAL & $56.050 .000,00$ & & & & \\
\hline
\end{tabular}

Setelah mendapatkan biaya yang diperlukan tiap aktivitas, maka dirinci lagi biaya aktivitas tiap satuannya, sehingga mendapatkan poll rate yang akan menjadi dasar harga untuk tiap aktivitas.

\subsubsection{Menghitung Biaya Tidak Langsung yang Dialokasikan ke Produk}

Tabel 7. Biaya Tidak Langsung yang Dialokasikan ke Produk

\begin{tabular}{|c|c|c|c|c|c|c|c|c|c|}
\hline $\begin{array}{c}\text { SI/ } \\
\text { Aktivitas }\end{array}$ & ADS & SDS & AZDS & MSP & MK & $\mathrm{JU}$ & MPP & LK & RK \\
\hline $\mathrm{K}$ & $534.883,72$ & $1.000 .000,00$ & $488.372,09$ & $790.697,67$ & 116.279 & $209.302,33$ & $232.558,14$ & $465.116,28$ & $116.279,07$ \\
\hline$P$ & $801.282,05$ & $320.512,82$ & $480.769,23$ & $160.256,41$ & 641.026 & $160.256,41$ & $480.769,23$ & $320.512,82$ & $801.282,05$ \\
\hline AS & $415.254,24$ & $498.305,08$ & $83.050,85$ & $83.050,85$ & 415.254 & $166.101,69$ & $415.254,24$ & $1.245 .762,71$ & $373.728,81$ \\
\hline $\mathrm{DF}$ & $1.278 .688,52$ & $213.114,75$ & $319.672,13$ & $532.786,89$ & 745.902 & $852.459,02$ & $959.016,39$ & $426.229,51$ & $213.114,75$ \\
\hline DP & $746.987,95$ & $74.698,80$ & $448.192,77$ & $522.891,57$ & 186.747 & $261.445,78$ & $112.048,19$ & $336.144,58$ & $186.746,99$ \\
\hline WH & $985.714,29$ & $514.285,71$ & $42.857,14$ & $85.714,29$ & 257.143 & $385.714,29$ & $128.571,43$ & $300.000,00$ & $42.857,14$ \\
\hline $\mathrm{PJ}$ & $697.826,09$ & $465.217,39$ & $930.434,78$ & $1.163 .043,48$ & 1.628 .261 & $465.217,39$ & $2.093 .478,26$ & $1.163 .043,48$ & $697.826,09$ \\
\hline $\mathrm{CS}$ & $909.638,55$ & $727.710,84$ & $545.783,13$ & $727.710,84$ & 363.855 & $636.746,99$ & $545.783,13$ & $363.855,42$ & $181.927,71$ \\
\hline I & $268.456,38$ & $536.912,75$ & $859.060,40$ & $295.302,01$ & 429.530 & $295.302,01$ & $241.610,74$ & $214.765,10$ & $107.382,55$ \\
\hline $\mathrm{T}$ & $874.038,46$ & $291.346,15$ & $485.576,92$ & $679.807,69$ & 194.231 & $485.576,92$ & $97.115,38$ & $582.692,31$ & $679.807,69$ \\
\hline TOTAL & $7.512 .770,25$ & $4.642 .104,31$ & $4.683 .769,46$ & $5.041 .261,70$ & 4.978 .228 & $3.918 .122,83$ & $5.306 .205,14$ & $5.418 .122,21$ & $3.400 .952,86$ \\
\hline
\end{tabular}

Pool rate digunakan untuk menghitung biaya yang dibutuhkan dengan mengalikan jumlah satuan pada tiap aktivitas.

\subsubsection{Menghitung Total Biaya Tiap Unit Langsung dan Tak Langsung}

Tabel 8. Total Biaya Tiap Unit Langsung dan Tak Langsung

\begin{tabular}{|c|l|r|r|r|}
\hline No & Jenis SI & Biaya Langsung & Biaya Tak Langsung & Biaya Total \\
\hline 1. & ADS & $577.472,53$ & $689.448,67$ & $1.266 .921,20$ \\
\hline 2. & SDS & $209.157,51$ & $1.127 .732,08$ & $1.336 .889,59$ \\
\hline 3. & AZDS & $2.497 .802,20$ & $786.564,05$ & $3.284 .366,25$ \\
\hline 4. & MSP & $859.340,66$ & $411.801,57$ & $1.271 .142,22$ \\
\hline 5. & MK & $1.164 .010,99$ & $786.564,05$ & $1.950 .575,04$ \\
\hline 6. & JU & $696.428,57$ & $670.259,71$ & $1.366 .688,28$ \\
\hline 7. & MPP & $309.706,96$ & $786.564,05$ & $1.096 .271,01$ \\
\hline 8. & LK & $522.893,77$ & $710.925,18$ & $1.233 .818,95$ \\
\hline 9. & RK & $92.747,25$ & $795.512,60$ & $888.259,85$ \\
\hline 10. & MSB & $1.615 .750,92$ & $786.564,05$ & $2.402 .314,97$ \\
\hline 11. & MA & $789.795,92$ & $786.564,05$ & $1.576 .359,97$ \\
\hline & TOTAL & $9.335 .107,27$ & $8.338 .500,08$ & $17.673 .607,35$ \\
\hline
\end{tabular}


Adapun hasil akhirnya didapat biaya total sebesar IDR 18.407.082,00 yang selanjutnya akan dihitung berdasarkan kompleksitasnya.

\subsection{Perhitungan Kompleksitas SI}

Penelitian dengan judul Pengukuran Metrik Kompleksitas Web Service [6] mengukur kompleksitas kode Sistem Informasi yang berupa Web Service yang mana case nya sama dengan penelitian ini. Adapun rumusnya adalah sebagai berikut:

\section{Codescale $=\left(0.637 \cdot \sum\right.$ Method $)+\left(0.258 \cdot \sum\right.$ Attribute $)+\left(0.105 \cdot \sum\right.$ Relation $)$}

Hasil yang didapat ukuran kompleksitas Web Service sekolah yaitu 3.472

\subsection{Perhitungan Unit Cost per Satuan Kompleksitas}

Setelah mendapatkan biaya total maka dihitung biaya per kompleksitasnya. Adapun biaya total yaitu sejumlah IDR 18.407.082,00, sedangkan kompleksitas nya berjumlah 3.472. Setelah dilakukan pembagian biaya total dengan kompleksitasnya maka didapat biaya untuk tiap kompleksitas yaitu sebesar IDR 5.301.

\section{KESIMPULAN}

Sistem pengelolaan pondok pada kebanyakan pondok pesantren di Indonesia tidak terlalu memperhatikan aspek manajemen, model proses bisnis ataupun pertumbuhan data. Pada praktiknya sistem informasi pondok pesantren kebanyakan hanya memperhatikan data santri sebagai daftar santri pondok, tidak lebih. Kurangnya kesadaran dalam memproses data akan membuat rencana pondok pesantren tidak terarah.

Sebenarnya jika diperhatikan lebih, data pada pondok pesantren dapat dimanfaatkan untuk memberikan keuntungan yang banyak pada pondok pesantren itu sendiri. Dengan data dan metrik, pihak pondok pesantren dapat memantau sudah sejauh mana pondok itu mencapai tujuannya, memprediksi anggaran yang lebih tepat, mengefisiensikan alokasi sarana dan prasarana pondok, pengoptimalan dalam pembelajaran dan sejumlah manfaat lainnya.

Ada banyak macam serta jenis sistem informasi yang beredar di masyarakat, yang paling populer digunakan adalah sistem informasi manajemen pondok berbasis web yang dirasa penggunaannya mudah dan tidak memerlukan komputer dengan spesifikasi tinggi. Seharusnya aplikasi berupa sistem informasi pondok pesantren dapat membantu meningkatkan mutu kualitas pelayanan di pondok dan juga dapat membantu para pengambil keputusan secara cermat menetapkan kebijakan strategi yang dipergunakan untuk mencapai tujuan dari pondok pesantren.

\section{DAFTAR PUSTAKA}

[1] (INKIND0)., Dewan Pengurus Nasional Ikatan Nasional Konsultan Indonesia. (2018.). Pedoman Standard Minimal Tahun 2019. 
[2] Dyah, P. (2018). Analisis Perhitungan Biaya Pengembangan Perangkat Lunak Pemerintah: Studi Kasus Pada Pusintek, Kementerian Keuangan. Subtansi Vol 2. Hilfi Lukman dkk. (2015).

[3] Perbedaan Perhitungan Unit Cost dengan Menggunakan Metode Activity Based Costing (ABC) dan Metode Doubel Distribution (DD) untuk Pasien Tb Paru Kategori 2 di Instalasi Rawat Jalan dan Rawat Inap Rumah Sakit Paru. . JSK Vol 2.

[4] Islahuzzaman. (2011). Activity Based Costing Teori dan Aplikasi. Bandung: Alfabeta.

[5] Mursyidi. (2010). Akuntansi Biaya: Conventional Costing, Just in Time, dan Activity-Based Costing. Bandung: PT Refika Aditama. Perpres Nomor 16 Tahun 2018. (n.d.).

[6] Setyaningrum, S. (2014). Analisis Perhitungan Biaya Satuan (Unit Cost) Dengan Model Activity Based Costing (Abc) Untuk Menentukan Standar Biaya Di SMK Negeri 3 Kota Tangerang Selatan 